\title{
Estrutura fina do espermatozóide de Mellita quinquiesperforata Leske (Echinodermata) do litoral norte do Brasil ${ }^{1}$
}

\author{
Edilson Matos ${ }^{2}$ \\ Patricia Matos ${ }^{3}$ \\ Laura Corral $^{4}$ \\ Carlos Azevedo ${ }^{4}$
}

\begin{abstract}
Fine structure of the spermatozoon of the Mellita quinquiesperforata (Echinodermata) of the Northern littoral of Brazil. The fine structure of the spermatozoon in the Mellita quinquiesperforata Leske, 1778 was studied. Collected from the Amazon region, were described by light and transmission electron microscopy. The spermatozoon consisted of a acrosome complex, nucleus, four to six mitochondria, two centrioles and flagellum. The acrosome was composed of a acrosome complex, the acrosomal vesicle and the subacrosomal space. The nucleus are composed by dense material. The middle piece contains 4-6 mitochondria which are arranged around the centrioles, the $9 p+0$, whose axoneme has the classic $9 p+2$ microtubular construction.

KEY WORDS. Equinodermata, Mellita quinquiesperforata, ultrastructure, spermatozoon
\end{abstract}

Os tipos de esperrmatozóides tem sido recentemente definidos pelo modo de transmissão e fertilização, relacionados a morfologia e filogenia, ocorrendo denominações, como espermatozóide primitivo para FRANZÉN (1983), de "aquatic sperm" para BACCETTI (1979) ou "aquasperm" para JAMIESON (1987). Os espermatozóides de Echinodermata são morfologicamente similares entre si, e referenciados como do tipo "primitivo", tendo entretanto características distintas. Este trabalho apresenta a descrição da estrutura fina do espermatozóide de Mellita quinquiesperforata Leske, 1778 do litoral norte do Brasil.

\section{MATERIAL E MÉTODOS}

Vários espécimes de $M$. quinquiesperforata foram colhidos nas praias de Ajuruteua (Bragança - Pará) $\left(00^{\circ} 50^{\prime} 55^{\prime \prime} \mathrm{S}, 4^{\circ} 36^{\prime} 30^{\prime \prime} \mathrm{W}\right)$, durante todo o ano. Observados macroscopicamente, dissecada a região ventral, foi comprovada em

1) Trabalho parcialmente subsidiado pela FCAP, UFPA e Fundação Engenheiro António de Almeida (Portugal).

2) Correspondências para: Departamento de Biologia Animal, Faculdade de Ciências Agrárias do Pará. Avenida Tancredo Neves, 66077-530 Belém, Pará, Brasil.

3) Departamento de Histologia e Embriologia, Universidade Federal do Pará. 66059-900 Belém, Pará, Brasil.

4) Departamento de Biologia Celular, ICBAS, Universidade do Porto. 4050 Porto, Portugal. 

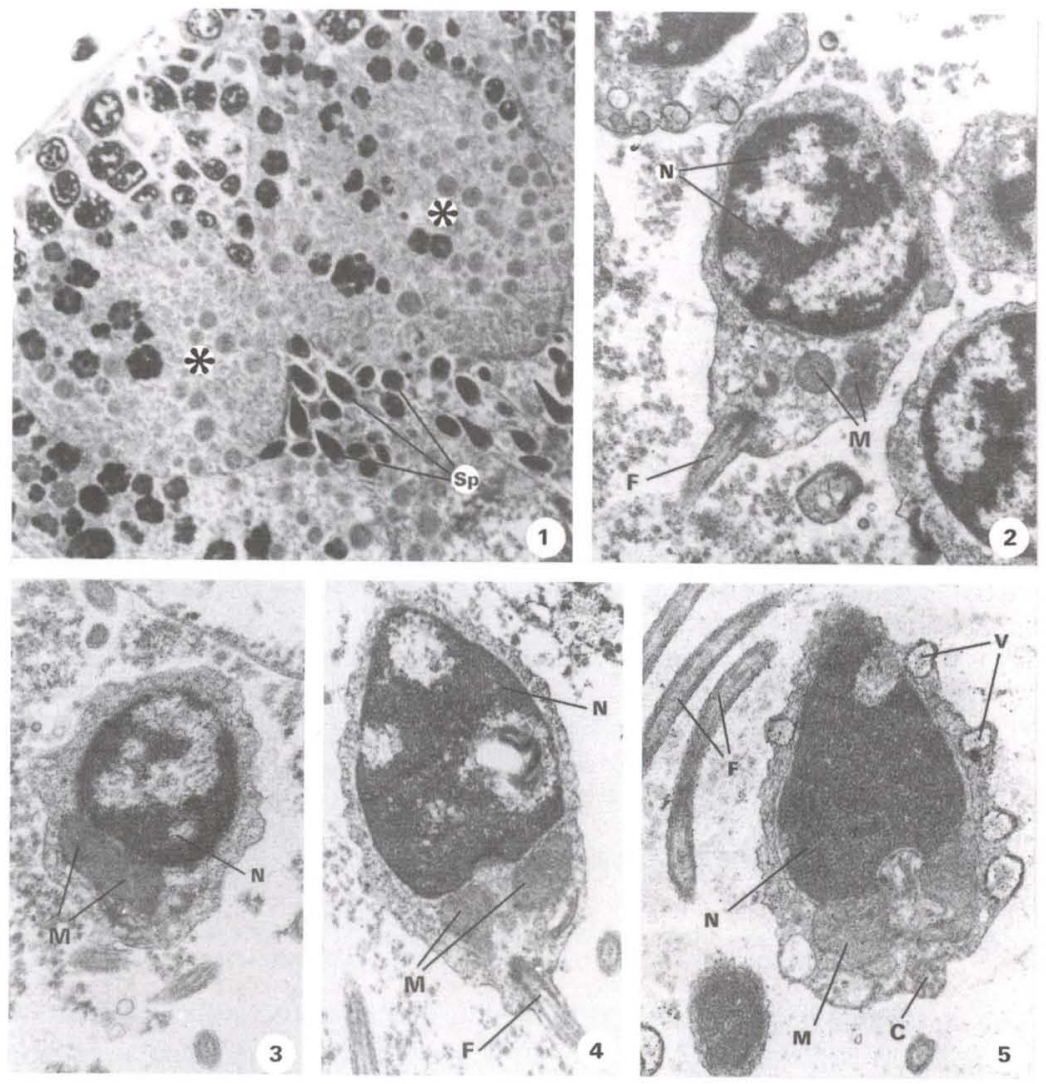

Figs 1-5. Mellita quinquesperforata (Echinodermata). (1) Corte semifino do testículo, observado em microscópio de contraste de interferência (Nomarski), mostrando cistos espermáticos $\left.{ }^{\star}{ }^{\star}\right)$ contendo espermátides. Numa porção mais interna são visiveis espermatozóides maduros - Sp; (2-4) cortes ultrafinos de células em diferentes fases que ocorrem durante a espermiogênese, caracterizada pela gradual condensação da cromatina do núcleo $(\mathrm{N})$, rearranjo das mitocôndrias (M) e formação do flagelo (F) (flagelogênese); (5) aspecto de uma espermátide tardia mostrando o núcleo denso $(\mathrm{N})$, mitocôndrias $(\mathrm{M})$ na posição basal, algumas vesículas (V) a periferia do citoplasma, corte transversal do centríolo (C). Junto observam-se cortes longitudinais de flagelos $(F)$.

microscopia estereoscópica, diferenças de coloração entre as gônadas, apresentando-se ligeiramente avermelhadas nas fêmeas e amareladas nos machos. Após esta identificação, pequenos fragmentos de gônada foram fixados pela técnica de GWO et al. (1996) modificada, que consiste na fixação em glutaraldeído a 5\%, adicionado de sucrose $7 \%$, em tampão cacodilato por $2 \mathrm{~h}$ a $4^{\circ} \mathrm{C}$. Os fragmentos foram lavados por 45 minutos em tampão cacodilato a temperatura ambiente e pós-fixados em tetróxido de ósmio tamponado por $1 \mathrm{~h} \mathrm{a} 4^{\circ} \mathrm{C}$. Em seguida, receberam três banhos em tampão cacodilato, por 15 minutos cada. Os fragmentos foram então desidrata- 
dos na série crescente de etanol e óxido de propileno, e embebidos em Epon 812. Cortes semifinos foram corados com azul de toluidina a $5 \%$ e observados em microscópio de interferência de fase Nomarski (DIC) e cortes ultrafinos foram contrastados com acetato de uranila e citrato de chumbo, e observados em microscópio eletrônico de transmissão JEOL 100CXII a $60 \mathrm{Kv}$.
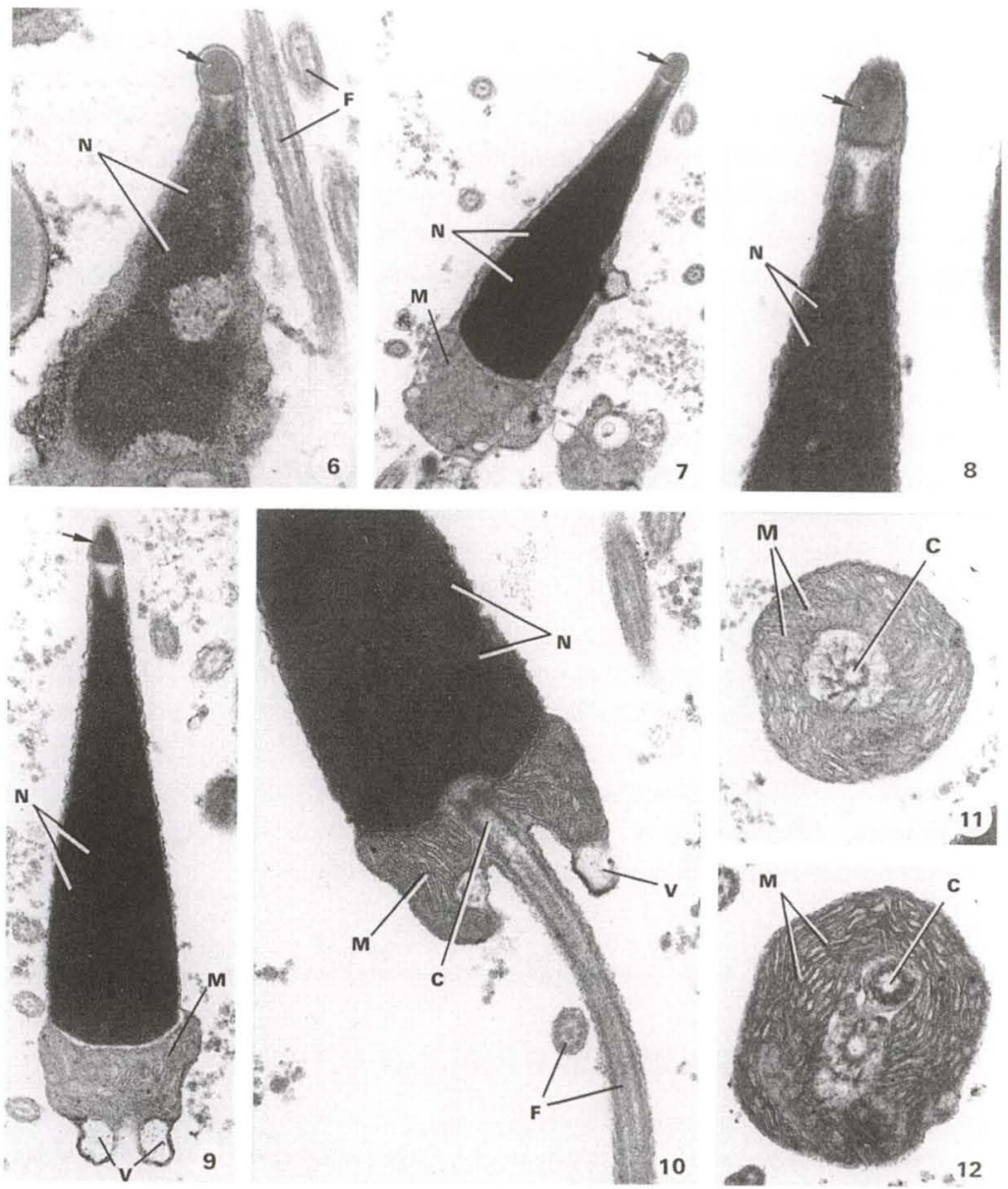

Figs 6-12. (6-9) Cortes ultrafinos mostrando a condensação do núcleo (N), a formação do acrosoma (setas) e o arranjo mitocondrial (M) que vai dar origem a peça intermediária do espermatozóide maduro. No final da espermiogênese pode-se observar as vesículas (V) e os centríolos $(C)$ localizados na base da peça intermediária; (10) detalhe ultraestrutural de um espermatozóide na fase final de maturação, mostrando o núcleo $(\mathrm{N})$, a peça intermediária com a mitocôndria (M), o centriolo (C) e as vesículas basais $(V)$. Observam-se também cortes longitudinais e transversais de flagelos $(F) ;(11-12)$ corte transversal da peça intermediária obtida em dois niveis diferentes, mostrando os centriolos $(C)$ na parte central da mitocôndria (M). 


\section{RESULTADOS}

Os espermatozóides apresentam-se constituídos de um complexo acrosômico, um núcleo, peça intermediária com 4-6 mitocôndrias, um par de centríolos e um flagelo (Figs 1-12). O complexo acrosômico consiste de duas partes: a vesícula acrosômica com aspecto cônico, e o espaço sub-acrosômico apresentando invaginação e depressão ao ápice nuclear (Figs 6-9). A parte anterior e posterior do núcleo, apresenta invaginações (Figs 6, 8 e 10), e a cromatina apresenta-se ligeiramente condensada na fase inicial (Figs 2-6) tornando-se altamente condensada, homogênea e compacta na fase mais adiantada (Figs 7-10). Na região posterior do núcleo, observamos a peça intermediária, envolvida por 4-6 mitocôndrias esféricas apresentando cristas e matriz, e envolvendo o complexo centriolar (Figs 5, 10-12). Um par de centríolos são envolvidos pelas mitocôndrias, e apresentam orientação perpendicular ao núcleo, com o clássico arranjo de 9+0 microtúbulos triplos (Figs 11-12). O flagelo exibe o típico $9+2$ microtúbulos.

\section{DISCUSSÃO}

A estrutura e desenvolvimento dos espermatozóide tem sido estudados em várias espécies de equinodermos (LONGO \& ANDERSON 1969; DAN \& SIRAKAMI 1971; ATWOOD 1974; BiCKell et al. 1980; YAMASHITTA 1983; BUCKLAND-NiCKS et al. 1984). Espermatozóides de estrela do mar, por exemplo, apresentam um acrosoma com componentes estruturais e funcionais bastante diferentes (MABUCHI \& MABUCHI 1973; SOUSA \& AZEVEDO 1985, 1986, 1988), mantendo a interação entre estes diferentes componentes e o ovócito para fertilização. O detalhamento das células espermáticas não tem sido analisadas ultraestruturalmente, presumindose que a formação acrosomal ocorra ainda na fase de espermátide (DAN \& SIRAKAMI 1971; JANSSEN 1984) demonstrando ser apropriada na fase final de maturação da espermátide em Marthasterias glacialis Linnaeus, por SOUSA \& AZEVEDO 1988, na interação espermatozóide/ovócito durante a fertilização.

AGRADECIMENTOS. Ao Sr. João Carvalheiro pelo serviço iconográfico.

\section{REFERÊNCIAS BIBLIOGRÁFICAS}

ATwOOD, D.G. 1974. Fine structure of spermatogonia, spermatocytes, and spermatids of the sea cucumbers Cucumaria lubrica and Leptosynapta clarki (Echinodermata: Holothuroidea). Can. Jour. Zool. 52: 1389-1396.

BACCETTI, B. 1979. The evolution of the acrosomal complex, p. 305-329. In: D.W. FAWXETT \& J.M. BEDFORD (Eds). The spermatozoon. Baltimore, Urban and Schwarzenberg Inc.

Bickell, L.R.; F.S. ChiA \& B.J. CrAwFord. 1980. A fine structural study of the testicular wall and spermatogenesis in the crinoid, Florometra serratissima (Echinodermata). Jour. Morphol. 166: 109-126.

BUCKLAND-NiCKS, J.; J. WALKER \& F.S. ChIA. 1984. Ultrastructure of the male reproductive system and of spermatogenesis in the viviparous brittle-star, Amphipholis squamata. Jour. Morphol. 179: 243-262.

Dan, J. C. \& A. Sirakami. 1971. Studies on the acrosome. X. Differentiation of the starfish acrosome. Dev. Growth differ. 13: 37-52. 
FRAN7.EN, A. 1983. Ultrastructural studies of spermatozoa in three bivalve species with notes on evolution of elongated sperm nucleus in primitive spermatozoa. Gamete Res. 7: 199-214.

Gwo, J.C.; C.H. Liou \& C.H. CiIENG. 1996. Ultrastructure of the spermatozoa of the Pacific oyster Crassostrea gigas (Mollusca, Bivalvia, Ostreidae). Jour. Submicrosc. Cytol. Pathol. 28 (3): 395-400.

JAMIESON, B.G.M. 1987. A biological classification of sperm types, with special reference to annelids and molluses, and an example of spermiocladisties, p. 311-332. In: H. MOHRI (Ed.). New horizon in sperm cell research. Tokio, Japan Scientific Societies Press.

JANSSEN, H.H. 1984. Development and ultrastructure of spermatozoa of Archaster typicus Mull. And Trosch. (Echinodermata, Asteroidea). Int. Jour. Invert. Reprod. Devl. 7: 333-344.

LONGO, F.J. \& E. ANDERSON. 1969. Sperm differentiation in the sea urchins Arbacia punctulata and Strongylocentrotus purpuratus. Jour. Ultrastruct. Res. 27: 486-509.

MABUCHI, Y. \& I. MaBuCHI. 1973. Acrosomal ATPase in starfish and bivalve mollusk spermatozoa. Expl. Cell. Res. 82: 271-279.

SousA, M. \& C. Azevedo. 1985. Acrosomal reaction and early events at fertilization in Marthasterias glacialis (Echinodermata: Asteroidea). Gamete Res. 11: 157-167.

. 1986. Cytochemical study on the spermatozoon and at early fertilization in Marthasterias glacialis (Echinodermata: Asteroidea). Biol. Cell. 56: 79-84.

. 1988. Fine structural study of the acrosome formation in the starfish Marthasterias glacialis (Echinodermata: Asteroidea). Tissue \& Cell. 20 (4): 621-628.

YamasintTA, M. 1983. A fine structural study of spermatogenesis in the brittle-star Ophiura sarsii (Echinodermata: Ophiuroidea), with a demonstration of the precocius formation of the acrosome. Jour. Fac. Sci. Hokkaido Univ. 23: 254-265.

Recebido em 01.VII.1999; aceito em 25.VIII.2000. 